\title{
Pensar a plasticidade na composição musical: esculpindo tempo, modelando escutas
}

Thinking of plasticity in the musical composition: sculpting time, modeling listenings

Gustavo Rodrigues Penha Universidade Federal de Mato Grosso do Sul penha.gustavo@gmail.com 


\section{Resumo}

Este artigo trata de alguns problemas composicionais musicais que têm insistido em atuar na prática composicional do autor e que se destacam devido aos seus modos de funcionamento no escoar contínuo de um fluxo temporal. Os problemas abordados foram levantados a partir de observações e reflexões de um pesquisador acerca de sua própria prática como compositor, mas não deixaram de ser trabalhados e verificados em variados contextos e situações que apontam para singulares modos de resolução dos problemas. Assim, através da análise de peças de diferentes compositores em contraponto com as composições do próprio pesquisador, o artigo contribui para se pensar a abordagem de alguns problemas composicionais em função de transformações plásticas dos objetos e texturas musicais em suas relações com o tempo, tido tanto como escoamento de um fluxo quanto como acontecimento.

\section{Abstract}

This paper will discuss some problems in musical composition that trouble the compositional practice of the author, and that stand out due to its operating modes in the continuity of a temporal flow. The problems were raised from some observations and reflections made by a researcher about his own practice as a composer, but they also were explored and questioned in several contexts that point to singular compositional ideas. Thus, through analysis of pieces of different composers in contrast with the researcher's compositions, this paper contributes to thinking about some compositional problems such like the function of plastic transformations of objects and musical textures in their relations with time, seen both as flow and as an event.

Keywords: Music Composition; gesture; compositional problem; time.

Palavras-chave: Composição musical; gesto; problema composicional; tempo. 
O trabalho composicional - seja ele mais ou menos individual ou coletivo, solitário ou colaborativo - ocorre por meio da criação e resolução de problemas que emergem a partir de um encontro, ${ }^{2}$ ou ainda do cruzamento de variados encontros. Os encontros são de várias ordens: entre pessoas, obras, grupos, ideias, imagens de todo tipo, e provocam, ao acontecer, conexões mais ou menos novas e improváveis. $\mathrm{E}$, por se desdobrarem mais ou menos ao acaso e imprevisivelmente, como consequência de um encontro, os problemas composicionais clamam pela participação de toda uma rede de colaboradores, de intercessores, de todo um grupo de "amigos-cupins" (OLIVEIRA, 2003), que aponta e adiciona tal ou qual ponto de vista que muda, continuamente, a configuração dos problemas, ${ }^{3}$ o que instiga a busca de uma nova solução a cada novo caso. Assim, pode-se pensar a ideia de que abordar problemas composicionais discursivamente e a posteriori, ou seja, reflexivamente, implica o rastreamento de marcas, traços e modos de participação pelos quais diferentes coletividades atuaram em vistas da colocação e da resolução dos problemas, por mais aparentemente solitário que tenha sido tal trabalho. É, portanto, em função de um tal rastreamento que este artigo se espraia.

Um problema que tem sido importante em meu processo composicional diz respeito à produção de um contínuo processo de modificação de modos de escuta ao longo de uma peça, seja pela transição gradual entre modos de escuta distintos, seja por sua súbita justaposição. Trata-se de uma operação que busca conduzir pouco a pouco a escuta por diferentes modos perceptivos, de maneira a fazer com que o foco e o modo de funcionamento da escuta variem de acordo com os materiais em ação e seus respectivos comportamentos. Assim acontece em per suonare in un teatro vuoto (PENHA, 2012), para quarteto de cordas, que se inicia com uma linha melódica que, apesar de fragmentada entre os instrumentos, propõe uma escuta que é principalmente melódica (ainda que não deixando de atuar nas dimensões timbrística e espacial) e que gradualmente se direciona para uma escuta interválica, que prioriza a sobreposição resultante da permanência de uns sons sobre outros (Fig. 1). O que interessa nesse processo é, portanto, a mudança do foco da escuta, a passagem de um modo de escuta a outro. Entretanto, para efetivamente se alterar o foco da escuta, não basta a simples distinção de estados sonoros, sendo importante também a distinção do que está perceptivelmente em jogo em determinado momento da escuta, quais níveis perceptíveis estão relevantemente em ação em cada um desses estados sonoros. É assim que são produzidas variações dos modos de escuta, dos modos de percepção ao longo de uma composição musical. É pela exploração de determinados elementos que se sobressaem uns com

2 Sobre o conceito de encontro, ver: Deleuze (2017[1968], p. 259-304, Orlandi (2018) e Zourabichvili (2016[2014], p. 73-75).

3 Essa ideia da contínua renovação das configurações dos problemas, em função da heterogeneidade de seus componentes e de sua abertura a um fora, possui ressonâncias com as ideias de metamodalização, em Guattari (1992) - "[...] o que distingue uma metamodelização de uma modelização é, assim, o fato de ela dispor de um termo organizador das aberturas possíveis para o virtual e para a processualidade criativa" (GUATTARI, 1992, p.44) - e de metastabilidade, em Simondon (2010[1962], p.157-176). 
relação aos outros que as escutas se modificam continuamente e se definem enquanto melódica, espectral, rítmica, espacial, textural, interválica, contrapontística etc.



Fig. 1: Trecho da seção inicial de per suonare in un teatro vuoto (PENHA, 2012), para quarteto de cordas

Do ponto de vista da relação entre composição e pesquisa, ou de uma aplicação da ideia de pesquisa-criação, ${ }^{4}$ que considera que composição e pesquisa são atividades especulativas que se alimentam mutuamente com vistas à criação de novos problemas - teóricos, práticos ou teórico-práticos -, o estudo do conceito de solfejo, como parte da minha tese de doutorado (PENHA, 2016), nasceu justamente de uma inquietação acerca dessa possibilidade de modificação dos modos de escuta ao longo de escoamento temporal de uma composição musical. A ideia que daí decorreu, que foi gradualmente elaborada ao longo da tese, é a de que a cada modo de escuta, compreendido como uma constelação de efeitos perceptivos, corresponde uma lógica composicional, que esculpe e dá a ouvir tais ou quais imagens perceptíveis. Ou seja, entre um conjunto de efeitos perceptivos e a lógica composicional que o produz (que pode também ser uma lógica interpretativa, performática), há uma relação que pode ser compreendida como um solfejo. Assim, então, a elaboração conceitual desenvolvida na tese, que dá novos ares e permite uma ampliação de alcance ao conceito de solfejo (tão desgastado pela habitualidade enrijecida de um ensino musical conservador), se tornou possível devido à minha atuação direta em uma prática composicional musical, ao mesmo tempo em que tornou possível novas experimentações propriamente composicionais. É nesse sentido que a pesquisa-criação implica o fazer (composicional musical, no caso) como etapa e procedimento fundamentais no desenvolvimento da pesquisa científica, ao mesmo tempo em que torna a elaboração conceitual e a reflexão sobre a prática, com

"[...] a pesquisa-criação inverte a relação do projeto com o saber. Ela se situaria sobretudo do lado do não sabido, visto que a criação implica não saber com precisão aquilo que se busca. É esta lacuna que permite o surgimento do inesperado, de uma surpresa. A pesquisa-criação se concebe mais como uma caminhada em direção ao desconhecido do que como uma expedição rumo ao saber, que é próprio da pesquisa. O valor de verdade ou a validação repousa sobre aquilo que foi descoberto durante o fazer, que foi objeto de uma explicitação devido a uma iniciativa de explicitação" (PAQUIN, 2014, p.24). Ver também: Pace (2020 [2015]). 
suas narrações e discursividades mais ou menos explicativas e explicitativas, elementos constitutivos do próprio processo criativo.

Como exemplo das potencialidades advindas das alterações de modos de escuta ao longo da escuta de uma peça, interessam-me as relações e diferenças entre monodia, homofonia, heterofonia e polifonia na escrita composicional. A ideia de trabalhar, na escuta, com a passagem de uma textura a outra tem sido um importante fator para o controle da dinamicidade e da dramaticidade de algumas peças. Da textura heterofônica, em comparação com a homofonia e a polifonia, me interesso principalmente pelos efeitos que produz na memória de curto prazo, por meio de microvariações, agitações, ornamentações, imitações rápidas e mais ou menos distorcidas, que perturbam a linearidade de uma melodia principal, criando algumas fendas na escuta melódica, em favor da abertura a outros modos de escuta, ou seja, fazendo com que os motivos componentes de uma melodia sejam continuamente apreendidos e esquecidos no seu próprio desenrolar por mudanças de foco causadas por diferenças timbrísticas, espaciais, rítmicas, de curvas, perfis, cores, harmonicidade etc. Tais procedimentos de coloração, ao produzirem essas quebras, fendas, vãos, atuam como regiões de transientes caóticos que fazem a escuta saltar por entre variadas sensações e percepções, produzindo constantemente novas conexões que perturbam a linearidade da escuta de notas sucessivas executadas por um timbre mapeado e individualizado de um instrumento, voz ou combinação de corpos sonoros. Já em caminhos, passagens e saídas (PENHA, 2008), como que por tateamento, havia uma atenção especial às variações heterofônicas das linhas. É assim também que se desenrola uma distribuição timbrística heterofônica em zanzando em zigue-zague (PENHA, 2014c), numa linha que se colore variadamente ao longo de seu decorrer, criando, nas microvariações, pequenos objetos e personagens que ganham mais ou menos permanência na paisagem (Fig. 2).



Fig. 2: Trecho de escrita heterofônica e de distribuição timbrística em zanzando em zigue-zague (PENHA, 2014C) 
Outro problema composicional sobre o qual tenho refletido e trabalhado, que também possui um caráter temporal, diz respeito à exploração de uma certa gestualidade física do instrumentista, por meio, por exemplo, da repetição de um determinado padrão [pattern] de movimentação dos dedos - seja num teclado, num espelho de instrumento de cordas ou nos orifícios de um tubo - que cria como que um motivo, não de ordem melódica, mas um motivo gestual. Essa ideia de um motivo gestual caracterizado pela repetição de uma determinada movimentação de dedos pode ser encontrada, por exemplo, nos motivos em semicolcheia presentes na Giga da Suíte I para violoncelo solo de J. S. Bach, ou no Allegro da Sonata VI para violoncelo e baixo contínuo de Francesco Geminiani. É claro que, em ambos os exemplos, as relações intervalares e as relações entre os valores de duração das notas poderiam ser abordadas enquanto constitutivas de motivos melódicos, mas o que efetivamente os singulariza e os caracteriza como motivos gestuais é a repetição de um determinado padrão de movimentação dos dedos da mão esquerda do violoncelista, de um rápido gesto físico produzido pela variação linear e sequencial de pressão dos dedos 1-2-4 ou 1-3-4 da mão esquerda sobre o espelho do instrumento. A repetição do padrão gera um ritmo que distingue esse gesto físico instrumental como um motivo gestual, um personagem efetivamente. É como se houvesse uma autonomização de um gesto musical e corporal, que é tornado personagem pelo ritmo nascido de sua repetição. Visto assim, como personagem, personagem rítmico, o motivo gestual atua explorando as variáveis dos distintos parâmetros que Ihe são implicados, como velocidade, tessitura, amplitude, intervalo entre repetições, quantidade de presença na textura global etc.

Também no Estudo no 15, White on White, para piano solo de György Ligeti, é possível observar essa ideia de exploração de um determinado motivo gestual físico-instrumental. A escrita da primeira parte da peça implica que a mão esquerda, a uma oitava abaixo, imite em cânone a movimentação realizada pela mão direita. O que é singular nesse cânone é que sua construção não se restringe a imitar somente a melodia diatônica, resultante da sequência das notas mais agudas da movimentação da mão direita. É a própria movimentação da mão direita que é imitada, movimentação que consiste na execução de uma nota em alternância com a execução simultânea de outras duas notas, produzindo um quase-contínuo movimento de abrir e fechar as mãos que percorre toda a primeira seção da peça. Essa alternância na execução de uma e duas notas, operando simultaneamente ao cânone, produz uma regular textura coral a três vozes na qual está implicada, portanto, a repetição constante de um determinado movimento físico que deixa uma marca na textura global e que se define, assim, como um motivo gestual, justamente pela sua permanência e sua participação no escoamento do fluxo sonoro.

Em estudo sobre gravitação (PENHA, 2013) (Fig. 3) e per suonare in un teatro vuoto (PENHA, 2012), ambas escritas para quarteto de cordas, me utilizei de um rápido gesto físico dos dedos da mão esquerda em movimento descendente, correspondente à execução de um fragmento de três ou quatro notas de uma escala diatônica realizada sobre uma mesma corda (fragmentos de quatro notas são usados nos casos de presença de corda solta). O motivo gestual é então definido pela repetição de um movimento rápi- 
do, linear e sequencial da pressão dos dedos 4-3-1 ou 4-2-1 da mão esquerda sobre o espelho do instrumento (Fig. 3). É um motivo que, se executado velozmente, possui um alto índice de energia cinética. É também um gesto físico idiomático, que está em estrita conexão com a prática tradicional de execução dos instrumentos de cordas com arco, seja vista a abundante presença da escrita de tais movimentos escalares para esses instrumentos. Trata-se, portanto, de um motivo gestual que "está na mão", que é simples, facilmente executável e que faz parte do repertório gestual de qualquer músico de instrumento de cordas; é banal, assim como outros tantos gestos tratados por si só. Mas o que faz esse motivo gestual gerar interesse para a escuta e entrar num modo operacional maquínico são as microvariações das aberturas de posição e os deslizamentos dos dedos da mão esquerda - que implicam um ambiente microtonal e que determinam algumas tendências direcionais na textura global -, assim como o contínuo cruzamento no plano frequencial das linhas repetidoras do motivo - movimentação que possibilita o deslocamento do foco da escuta, de maneira a fazer com que o aspecto melódico das linhas não se sobressaia, em favor da constituição de uma escuta textural. Já em nenhum, nenhuma (PENHA, 2010b), para piano solo, um mesmo motivo gestual é realizado na região central do instrumento simultaneamente pela mão esquerda nas teclas pretas e pela mão direita nas teclas brancas. O que se cria nessa situação é a constante alternância entre uma escuta melódica e uma escuta textural, alternância que é efetivada não somente pelo cruzamento contínuo das linhas, mas também pelas suas variações de velocidade e pelo uso do pedal de sustentação do instrumento (PENHA, 2010a).

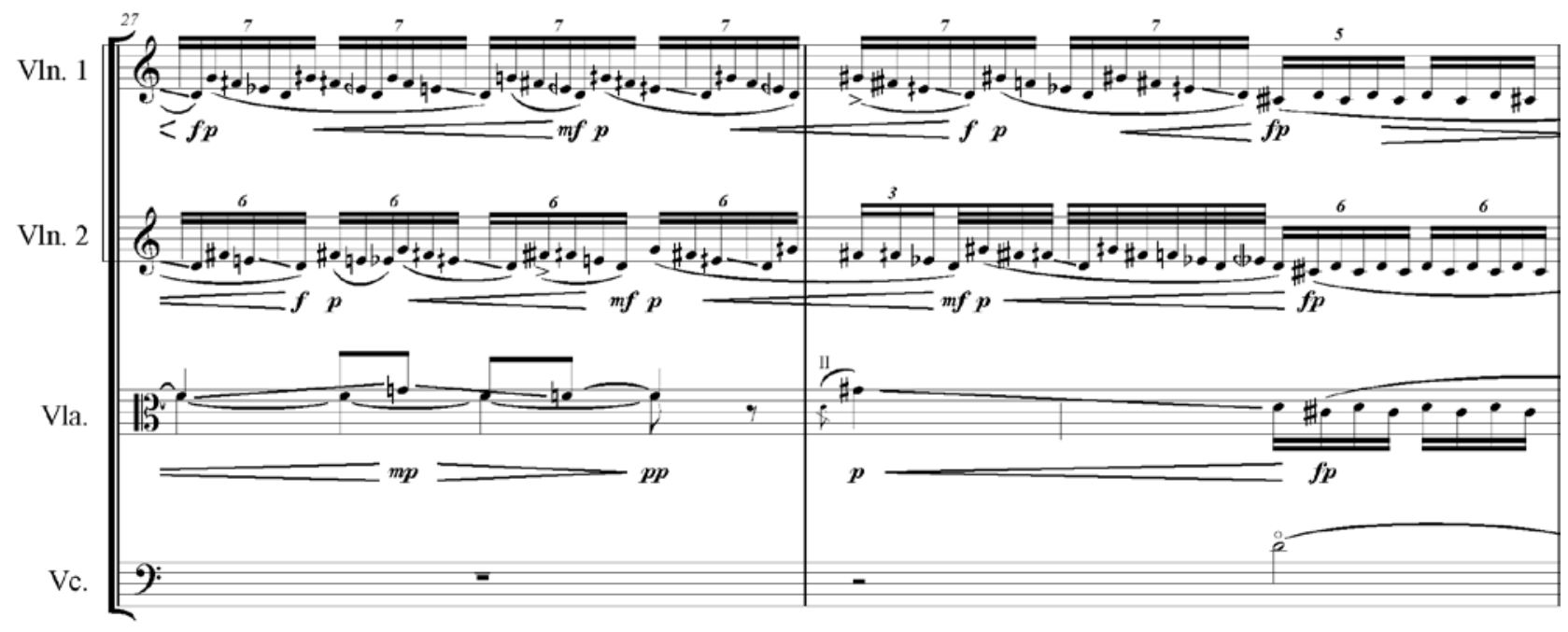

$p p$

Fig. 3: Compassos 27 e 28 de estudo sobre gravitação (PENHA, 2013)

Os efeitos sonoros e texturais gerados pelo cruzamento constante entre as vozes têm me interessado bastante na escrita instrumental, principalmente por possibilitarem que as linhas não se destaquem individualmente umas das outras na escuta, mas antes constituam sonoridades que fazem com que sejamos atravessados por modos de escutas distintos daqueles próprios à escuta melódica. Cruzar vozes é usar linhas melódicas para costurar, bordar, emaranhar fios. Criar tecidos sonoros de diferentes intensidades 
de vibração energética, variáveis de acordo com as técnicas instrumentais que acompanham o cruzamento das vozes, assim como com planos harmônicos e de transientes resultantes das relações entre sustentações de alturas mais ou menos longas e modos de ataque instrumentais mais ou menos ruidosos. Assim, as qualidades dos tecidos sonoros são talhadas de acordo com os modos de costurar as linhas e os materiais com os quais se costura, o que implica uma vastíssima variedade e variabilidade têxtil-sonora potencialmente produzível e explorável na escrita.

Este gosto particular por sonoridades formadas por vozes entrelaçadas foi, sem dúvida, amplamente determinado pelo estudo da obra de Ligeti, principalmente pelos variados contextos de formações instrumentais em que ele aplica a técnica de cruzamento de vozes e pelos consequentes efeitos resultantes da maleabilidade da técnica frente a contextos técnicos e instrumentais os mais diversos.

Para exemplificar essa ideia, poderiam ser citadas diversas obras de Ligeti, Xenakis, Scelsi, mas pretendo apontar para uma peça vocal do século XIV, chamada O Virgo Splendens, de compositor anônimo (2004 [1396-1399]) e que está presente no Llibre Vermell de Montserrat. A peça consiste numa longa linha melódica dividida em módulos de tamanhos iguais que atuam numa mesma tessitura, num mesmo modo harmônico e que terminam todos numa nota longa. Os módulos devem ser cantados em cânone. Assim, a peça se inicia com a realização de uma voz que é imitada pela outra assim que inicia o módulo seguinte. Como exemplo, tomaremos a análise de uma interpretação a três vozes, que possibilita que aconteça um significativo número de cruzamentos na textura global, produzindo, assim, efeitos perceptivos singulares na escuta. Dessa maneira, se observarmos a transcrição da peça para um gráfico que atua numa lógica neumática, poderemos apontar para as variações de configuração dos diferentes momentos a partir da repetição sequencial e sobreposta de uma mesma linha melódica (Fig. 4). Em cada intervalo temporal em que se desenrola um módulo, produz-se, portanto, um novo modo de povoamento do espaço, que é determinado pela sobreposição dos diferentes módulos que se repetem continuamente. É um processo de variação contínua no tempo que se efetua a partir da repetição e sobreposição deslocada de uma mesma linha melódica.

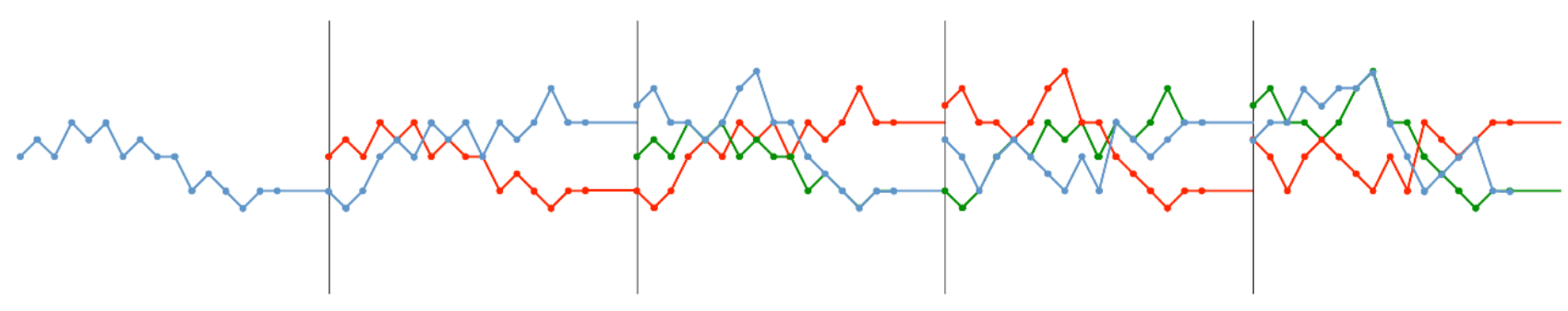

Fig. 4: Gráfico de movimentação das vozes em 0 virgo splendens. A linha azul corresponde à primeira voz, a vermelha, à segunda e a verde, à terceira.

Outro problema composicional que tem sido bastante importante para mim, e que tenho perseguido já há algum tempo (ou pelo qual tenho sido perseguido), é o de abertura e ocupação gradual do espaço. Em música, a abertura e ocupação gradual do espaço pode ser trabalhada em variados níveis, em diversos planos. Pode-se falar de 
espaço frequencial, espectral, de performance, do instrumento musical, da partitura ou outro suporte de escrita, mas também espaços econômicos, sociais, geográficos, filosóficos... Muitos são, portanto, os planos espaciais presentes em música, e em cada um é possível pensar modos próprios de abertura e ocupação, que variam de acordo com a variação rítmica dos personagens postos em jogo em cada plano. Os planos espaciais podem ainda se intermodular, criando compostos dinâmicos em que funcionam como distintos, mas indiscerníveis, uns dos outros. Ressalta-se ainda que a abertura e ocupação do espaço se apresentam como um problema composicional que se desenrola no escoamento contínuo de um fluxo temporal; o que caracteriza, portanto, sua logicidade temporal.

Vejamos, como um primeiro exemplo desse procedimento, uma peça de J. S. Bach, - Andante da Sonata II para violino solo sem acompanhamento, para melhor observar essa ideia de abertura e ocupação gradual do espaço. Um aspecto relevante na construção deste movimento da Sonata /l consiste na complexa ação do arco ao longo da peça, devendo articular continuamente um baixo de notas repetidas, simultaneamente à construção e manutenção de uma linha melódica cantábile mais aguda, de caráter mais livre e ligado (Fig. 5). É uma ação que exige do instrumentista uma alta desenvoltura técnica. Bach justapõe a essa singular ação do arco, acima descrita, alguns acordes de três ou quatro notas em cordas contíguas, que são tradicionalmente executados em arpejos no violino, devido à natureza própria do instrumento. Há então um jogo composicional no qual longos períodos de uma paisagem melódica, que é acompanhada por um baixo ritmicamente regular, são justapostos às sonoridades de ataques rápidos de arco arpejado, que não deixam de atuar na elaboração polifônica da peça e que também criam um novo ritmo, que nasce da relação de alternância entre a condução a duas vozes e os arpejos rápidos. A textura global da peça pode então ser descrita pela contínua movimentação simultânea de duas vozes, que funcionam numa relação de baixo e melodia, operando em contraste com a execução de um gesto físico-instrumental de arpejo rápido com o arco em cordas contíguas (Fig. 5). 




Fig. 5: Fac-símile do Andante em Dó Maior da Sonata II, em Lá menor de J. S. Bach

Com essa singular textura, Bach elabora uma especial ocupação do espaço próprio ao plano das cordas do instrumento. A peça se inicia no par de cordas graves do violino (Sol-Ré) e lentamente se direciona ao par agudo de cordas (Lá-Mi), para finalizar retornando ao par de cordas graves (Fig. 6). Bach não realiza tal curva dramática de uma única vez, num só fôlego, mas cria períodos nos quais são exploradas nuances de cada uma das regiões do instrumento. Há um constante avançar e retornar nos pares das cordas do instrumento, o que contribui no caráter gradativo da ocupação desse plano espacial na peça. Essa ocupação espacial contribui também para a construção da curva dramática da peça, ao fazer com que o trecho em que há maior tensão harmônica e dramática, o confutatio (a partir do quarto compasso da parte B, Fig. 5 e 6), corresponda ao trecho em que o par de cordas agudo é mais explorado e utilizado, fazendo com que a movimentação no plano das cordas esteja em estrita relação com o próprio arco dramático da composição. Assim, Bach constrói uma peça em que os períodos e frases são elaborados em estrita relação com um plano espacial do instrumento, ou seja, uma peça em que um complexo pensamento instrumental está implicado no próprio pensamento formal e de organização das alturas. 


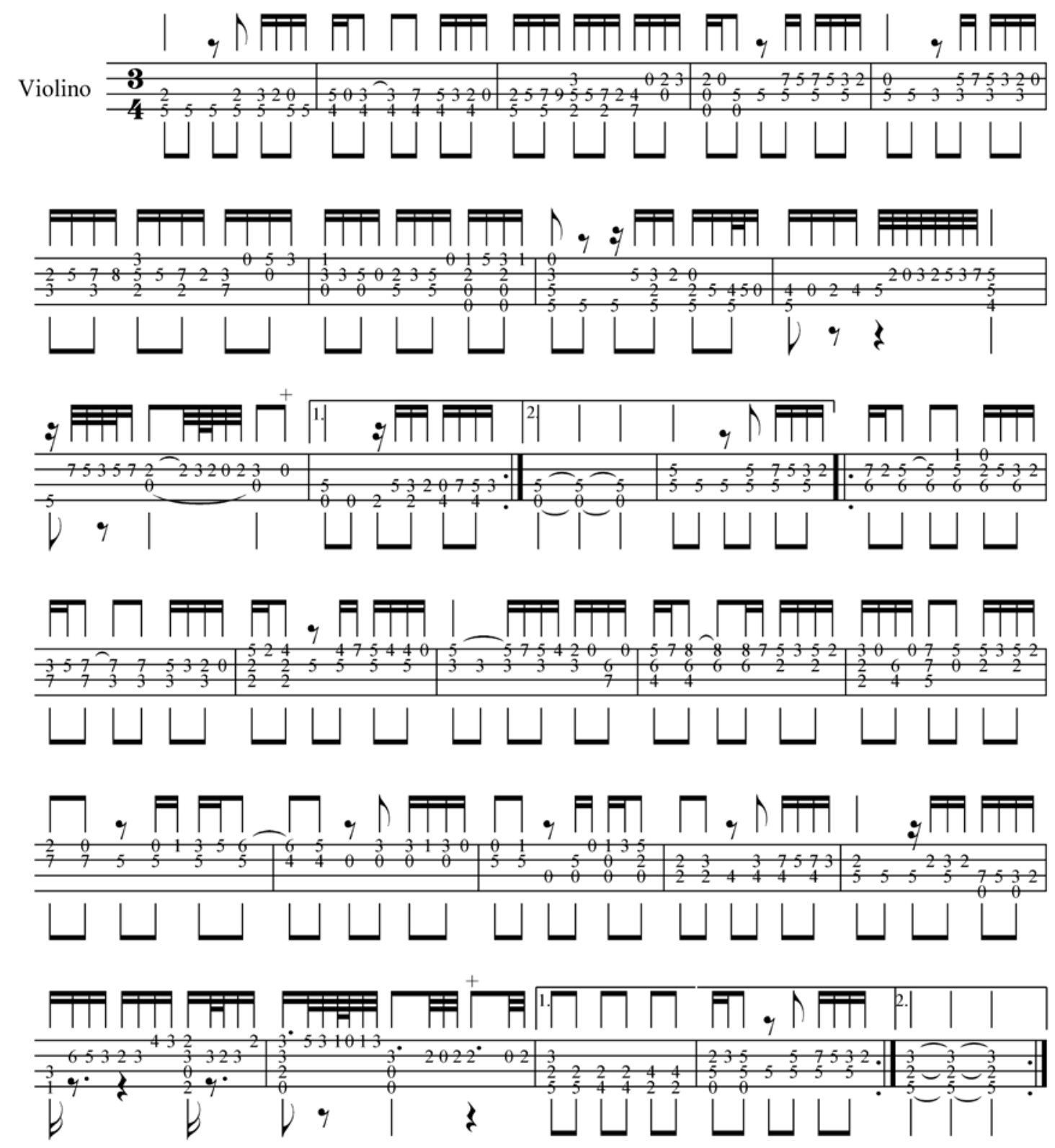

Fig. 6: Transcrição em tablatura do Andante em Dó maior da Sonata Il para violino solo de J. S. Bach

Em minhas peças tenho frequentemente pensado as potências e qualidades do meio técnico-instrumental a serem exploradas na escrita, em confronto com os modos de cruzar vozes aplicáveis à formação instrumental para a qual a peça está sendo escrita, para assim formar e transformar fluxos, texturas e massas sonoras sem vozes individuais reconhecíveis. Trata-se de pensar tanto a gestualidade física implicada nas ações instrumentais quanto a figuralidade dos movimentos de pontos e linhas em entrecruzamento contínuo, como fundamentais à caracterização dos estados texturais e de seus modos de transformação. Variações de velocidade, de direção e de traçado dos perfis motívicos, de comportamento rítmico, de quantidade de elementos sobrepostos ou aglomerados, dos modos de execução instrumental, dos modos de costura entre as vozes etc. são alguns dos fatores que produzem alterações dos modos expressivos que caracterizam afetivamente um desenrolar sonoro singular. Assim, a velocidade de mo- 
vimentação das linhas, por exemplo, contribui diretamente na expressividade afetiva de uma passagem musical. Em O Virgo Splendens, como vimos acima, o cruzamento entre as vozes se efetua homofonicamente e com as mudanças entre as notas realizadas de um modo não agitado, com intervalos longos o suficiente para caracterizar uma plácida prece de longas e ressonantes vogais cantadas em registros vocais confortáveis. Entretanto, podemos também pensar o modo homofônico de cruzamento entre as vozes sendo realizado em altíssimas velocidades técnico-instrumentais, como podemos encontrar no trecho final de estudo sobre gravitação (PENHA, 2013), escrita para quarteto de $\operatorname{cordas}^{5}$ (Fig. 7). Este trecho é marcado por um fluxo sonoro que realiza uma ampla e gradual varredura descendente de duas oitavas e uma quinta justa, aproximadamente, por meio de um costurar e bordar contínuo de vozes que repetem, com variações microtonais, pequenos fragmentos motívicos escalares de três notas e que aumentam pouco a pouco em quantidade, de duas para quatro linhas, na constituição da textura sonora. Trata-se, portanto, de uma conexão entre três ideias vistas até aqui: a abertura e ocupação gradual do espaço; a exploração de motivos gestuais; e o cruzamento contínuo de vozes. É uma sonoridade que, apesar de escrita homofonicamente tal qual $O$ Virgo Splendens, comporta afetos completamente distintos daquele da placidez de uma reza canônica, que se caracterizam e se apresentam nas microagitações extremamente rápidas das linhas (traçadas por grãos ou pontos de duração temporal de aproximadamente 104 ms cada, correspondentes ao valor da fusa, sendo a semínima = 72 BPM), pelos movimentos de dedos obsessivamente repetidos em estrias, ou grades, microtonais moventes, por uma ampla curva dinâmica que parte de um pianíssimo murmurado para se direcionar a um forte e violento uníssono sobre o Lá\$3 (nota da afinação padrão da primeira corda do violoncelo), assim como pelas qualidades sonoras metálicas devidas ao ataque do arco em posição de ponticello (Fig. 7).

5 Tal peça foi escrita com vistas à minha participação em um masterclass com o Quarteto Arditti durante o $42^{\circ}$ Festival Internacional de Inverno de Campos de Jordão, realizado em 2011, tendo sido revisada para uma execução na Sala St. Lukes, em Londres, pelo grupo Riot Ensemble, realizada em abril de 2013. 

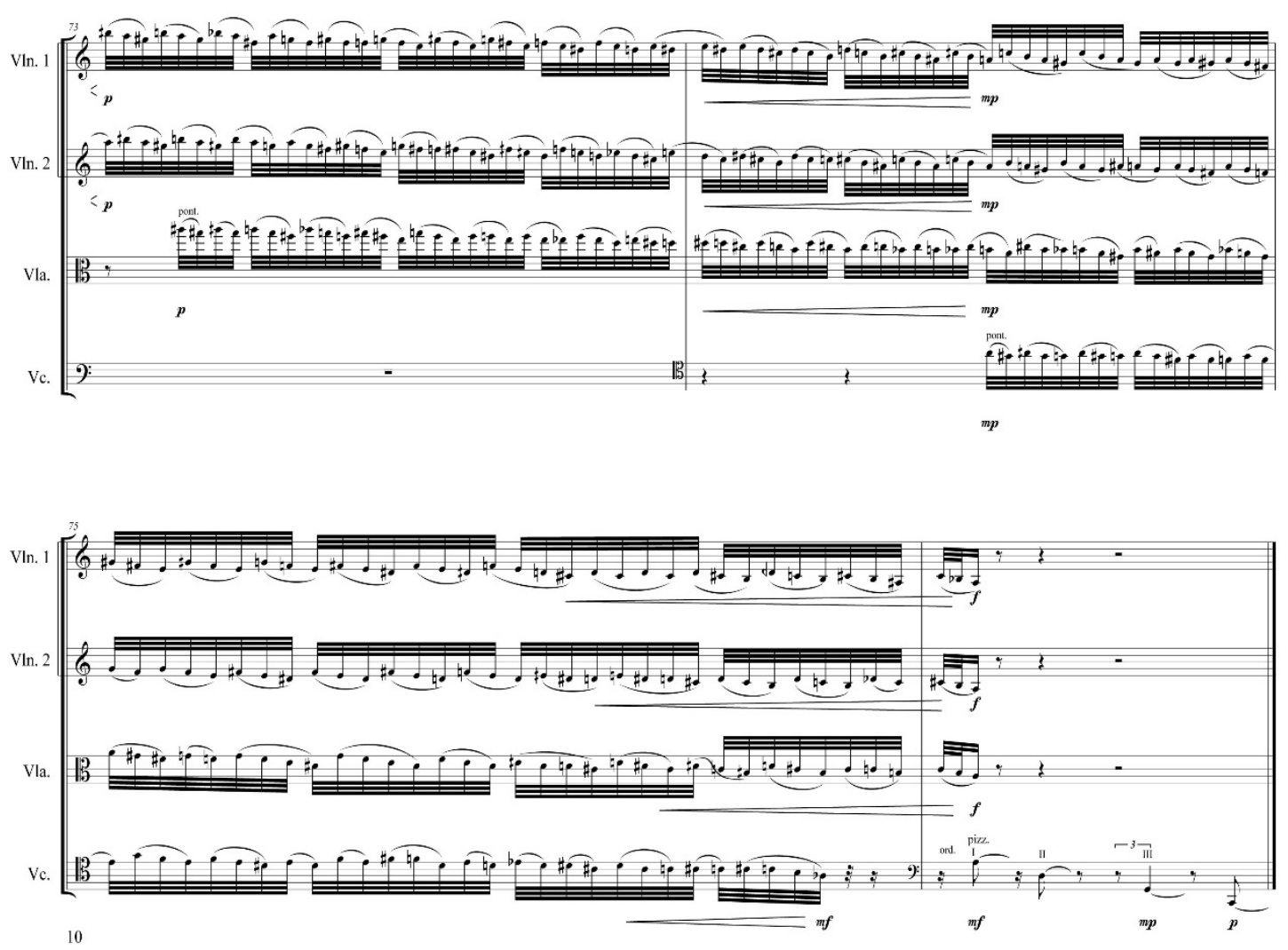

Fig. 7: Trecho de estudo sobre gravitação (PENHA, 2011), para quarteto de cordas

Já em per suonare in un teatro vuoto (PENHA, 2012), o cruzamento entre as vozes é responsável pela caracterização da segunda parte da peça (a partir do compasso 32), justamente num trecho que propõe um material que busca possibilitar ao ouvinte, através de um corte súbito, a saída das escutas melódica, interválica e heterofônica, gradualmente apresentadas na primeira parte. A peça foi construída a partir dessa ideia de organização temporal de variados modos de escuta, ou seja, da ideia de criar um fio condutor que fizesse com que a escuta variasse de acordo com as diferenças de dinamicidades implicadas nos materiais. Assim, a peça se inicia propondo uma silenciosa, calma e distante escuta melódica de uma frase pentatônica simples, executada em harmônicos pelas cordas, que vagueia pouco a pouco por entre os diferentes instrumentos pela técnica da distribuição timbrística. Aos poucos, algumas notas da melodia começam a permanecer umas sobre as outras, fazendo com que a escuta, que até então focava prioritariamente sobre as mudanças melódicas, passe a se atentar também às cores singulares de alguns intervalos harmônicos que se distendem mais ou menos longamente sobre a textura monódica pentatônica. É como se, com essas sobreposições de sons, a escuta melódica efetuasse um cruzamento com um modo de escuta de outra natureza, no caso, um modo de escuta interválico, que se atenta às cores, aos pesos, às rugosidades e às variadas qualidades dos diversos intervalos harmônicos entre notas, alturas ou sons tônicos entre si. Assim, já em seu início, como dito anteriormente, a peça propõe já um primeiro conflito entre modos de escuta, mais precisamente entre a escuta melódica e a escuta interválica harmônica. Em seguida, tendo a escuta melódica 
e a escuta interválica se consolidado como os modos principais de escuta da peça até então, um novo elemento é inserido, formado por pequenos ornamentos, fragmentos motívicos e de frases melódicas, que faz com que a escuta seja atravessada por um modo de escuta heterofônico, ligado às pequenas variações que ocorrem em curtos intervalos temporais com relação ao desenrolar de uma linha melódica principal. O modo de escuta heterofônico, como vimos, faz com que a continuidade e a linearidade da escuta melódica sejam perturbadas por outras escutas de coloridos, timbres, energias de transientes, perfis melódicos, ornamentos, que dão uma nova vida a materiais melódicos mais ou menos simples que têm constantemente renovados seus comportamentos e modos de variação pela exploração de uma pluralidade de qualidades sonoras, curvas dinâmicas, articulações, contornos e traçados motívicos, que põem a memória curta a operar intensiva e continuamente na escuta através de um processo em que a apreensão de novos elementos ocorre em simultaneidade com o esquecimento e apagamento de elementos anteriores na memória. É assim, portanto, que a primeira parte da peça se consolida, iniciando pela proposição de uma escuta melódica que se desenrola vagueando por entre os instrumentos, até cruzar mais adiante com uma escuta interválica e, ainda mais à frente, ser perturbada por uma escuta heterofônica. Essa primeira seção é então finalizada por uma longa nota em pedal que "resolve" e acalma a tensão anterior e que é interrompida pela súbita entrada de rapidíssimas vozes microtonais de violinos se entrecruzando homofonicamente entre si e produzindo, assim, uma escuta textural que rompe com a escuta melódica, fortemente atuante até então. A escuta textural não foca mais a atenção a linhas sonoras individualmente apreensíveis na escuta, mas, sim, à dinamicidade interna dos fluxos sonoros resultantes do cruzamento contínuo entre vozes (Fig. 8). O que determina a dinamicidade de tais fluxos sonoros são principalmente as velocidades de movimentação das linhas, seu âmbito de atuação e os modos de ocupar tal âmbito (por varredura, escalarmente, em zigue-zague, por bordaduras), as direcionalidades na tessitura, a densidade de grão e pontos e seus respectivos comportamentos rítmicos, os modos de costura e entrelaçamento entre as vozes, e, por fim, a energia articulatória ligada aos ataques de arco. São estes, portanto, alguns dos elementos que entram em variação na segunda parte de per suonare in un teatro vuoto (PENHA, 2012), num processo que busca conduzir o foco de atenção da escuta às potências e qualidades texturais talhadas, bordadas e costuradas pelo emaranhamento e embaraçamento incessante de linhas sonoras em movimentação rápida e contínua.

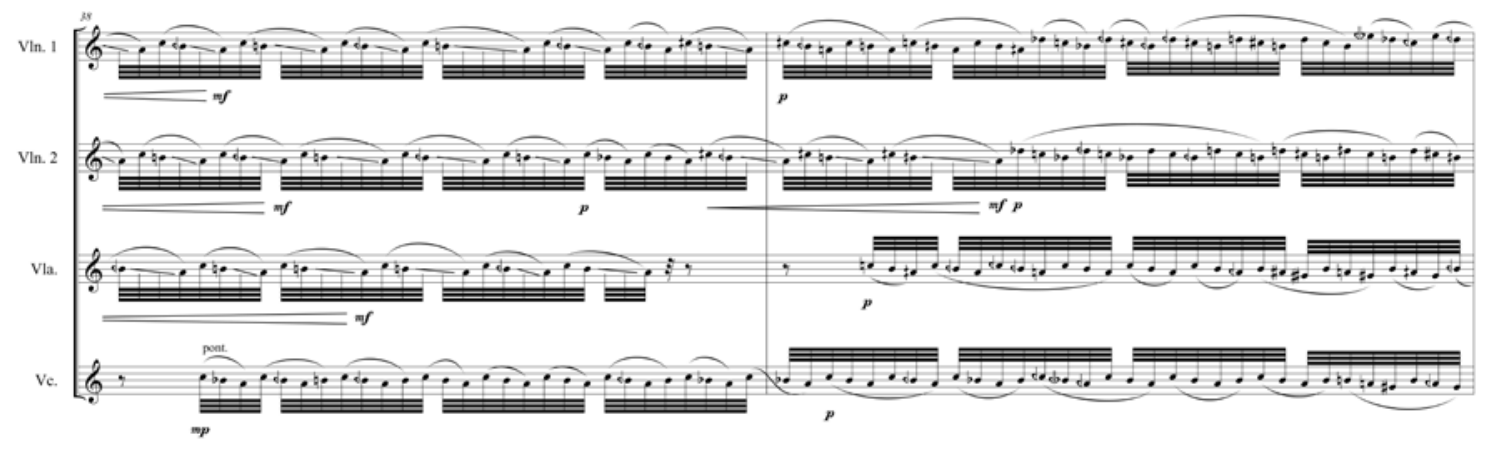

Fig. 8: Trecho de per suonare in un teatro vuoto (PENHA, 2012), para quarteto de cordas 
A questão do fraseado das linhas na escrita instrumental é ainda um outro problema ao qual tenho atentado, já desde minhas primeiras composições. É porque a cada modo de fraseado está implicado um mundo afetivo singular, mais ou menos constituído por cristalizações coletivas do tipo dos clichês, o que faz com que o fraseado de uma linha se apresente, à escuta, como um relevante aspecto da escrita. Foi, portanto, primeiramente pelo desejo de trabalhar com modos de frasear que não fossem explicitamente estilizados que essa preocupação com o fraseado foi despertada. Num primeiro momento, ainda durante a graduação, buscando me afastar de frases sincopadas ou nauseantemente cromáticas que então povoavam minha cabeça, foi no universo modal que busquei um certo refúgio, explorando linhas melódicas formadas por mistos de modos eclesiásticos, jazzísticos, nordestinos e de transposição limitada utilizados por Messiaen. ${ }^{6}$ Posteriormente, meu interesse fraseológico se dirigiu cada vez mais a ambientes microtonais, tanto privilegiando intervalos melódicos menores do que meio tom (Fig. 9, 10, 11 e 12), quanto trabalhando com movimentos de segundas e terças pouco maiores e menores do que as maiores e menores (como no violoncelo e na viola do segundo compasso da Fig. 10 ou nos violinos na Fig. 11), quanto por trilos que expandem e contraem sua tessitura (como no violoncelo na Fig. 11). Tal exploração de um fraseado microtonal tem sido frequentemente elaborado em conexão estrita às singularidades e potencialidades técnicas dos instrumentos para os quais estou escrevendo, buscando tanto explorar passagens que sejam "na mão" em uma determinada prática quanto desconstruindo fôrmas de mão por demais rígidas em tal ou qual técnica. Dessa maneira, tenho conseguido construir rápidos movimentos de dedos que percorrem grades intervalares microestriadas (ou mal temperadas) e que produzem, assim, um fraseado que nos aproxima mais a zumbidos de mosquitos e insetos (Fig. 11), ou por vezes a latidos de cachorro (Fig. 10), do que de cantos radiofônicos, de salas de concerto ou de shows mais ou menos midiáticos. Também os cantos de pássaros têm sido uma importante fonte de pesquisa para a busca por outros fraseados, como explorado em Vento sob os dedos (PENHA, 2014b), para flauta solo, em que diversos cantos de pássaros se cruzam e se chocam e se modulam assim uns pelos outros (Fig 12).



Fig. 9: Fraseado choroso no tímpano em presque un murmure sans son (PENHA, 2014a) 


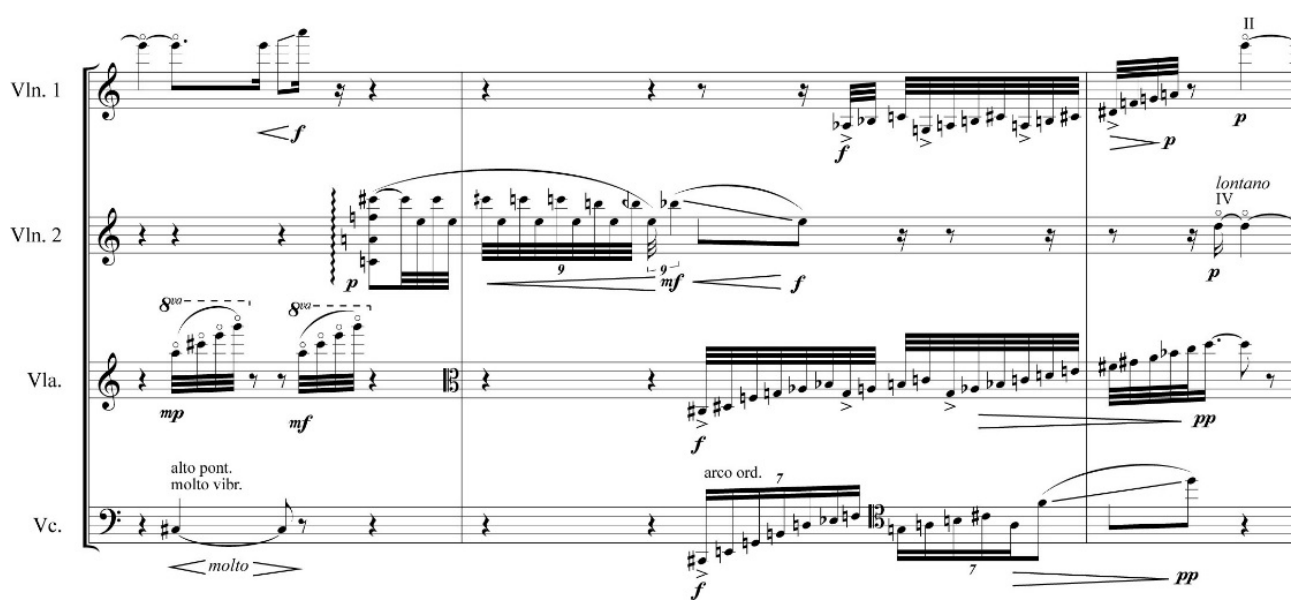

Fig. 10: Trecho de per suonare in un teatro vuoto (PENHA, 2012) em que é explorado um fraseado lamentoso e choroso no violino 2, seguido por um fraseado-cachorrão feito por ataques de arco em détachée fortes na região grave dos demais instrumentos.

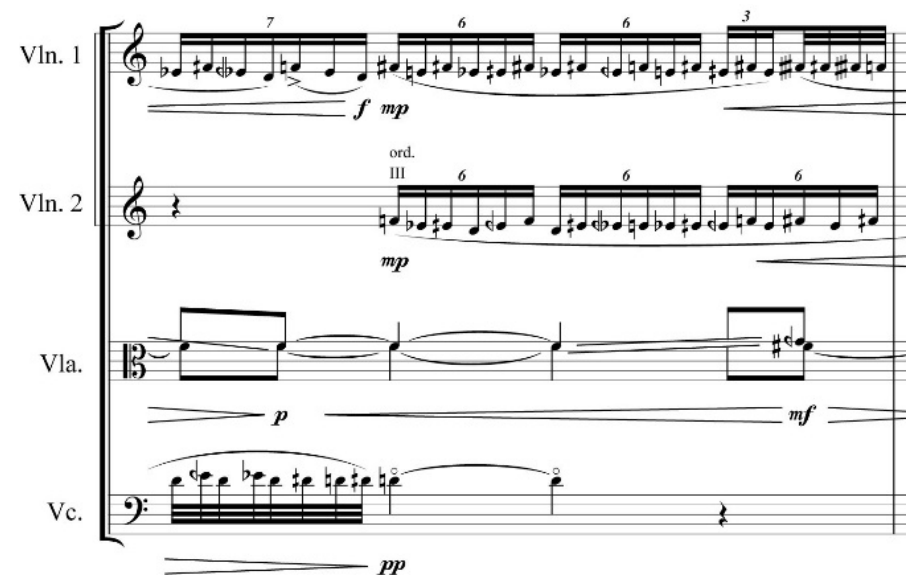

Fig. 11: Trecho de sobreposição de fraseados tipo mosquitos e insetos em estudo sobre gravitação (PENHA, 2013)

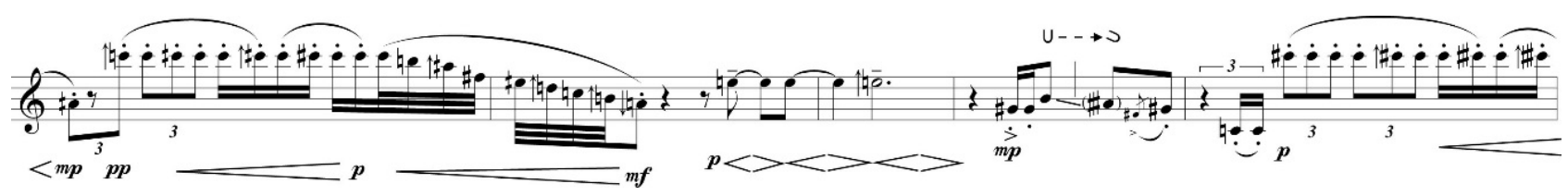

Fig. 12: Imbricação e justaposição de cantos de pássaros em Vento sob os dedos (PENHA, 2014b), para flauta solo

Lembro-me de um dia em estúdio, durante a gravação de caminhos, passagens e saídas (PENHA, 2008) pelo grupo Sonâncias, que um comentário da compositora e amiga Valéria Bonafé me deixou bastante intrigado, acerca do caráter plástico da escuta da peça. A sensação que tive foi a de que a Valéria tinha conseguido sintetizar em uma palavra toda uma problemática composicional que eu estava então trabalhando e que só viria a se potencializar com essa tomada de consciência possibilitada por seu comentário. ${ }^{7}$ Nunca busquei saber o que Valéria quis dizer exatamente com plástico, 
mas desde então fiquei com essa ideia de um "caráter plástico" na cabeça, como qualidade-potência, como afeto, a ser trabalhado composicionalmente, e como tal afeto se apresentava nas minhas peças. Em caminhos, passagens e saídas (PENHA, 2008), especificamente, peça à qual Valéria se referia, de fato houve um trabalho de busca de relações de choques entre objetos, perturbações tímbricas, bariolagens e trilos que contribuíam na produção de dinamicidade e variação da plasticidade da peça. Lembro-me especialmente de um trecho em que pensei em esticar um intervalo tal como um elástico, tensionando-o pouco a pouco. Busquei explorar essa ideia após ter lido o seguinte relato de Stravinsky (CRAFT, 2004 [1959], p.11-12) sobre um cômico sonho que havia então experimentado:

Deixe-me falar sobre um sonho que tive enquanto compunha Threni. Depois de trabalhar até muito tarde, uma noite, deitei-me ainda perturbado por um intervalo. Sonhei com ele. Tinha se tornado uma substância elástica que se esticava exatamente entre as duas notas que eu tinha escrito, mas embaixo de cada uma dessas notas, nas duas extremidades, havia um ovo, um grande ovo testicular. Os ovos eram gelatinosos ao tato (eu os toquei) e quentes, e eram protegidos por ninhos. Acordei sabendo que meu intervalo estava certo. (Para quem queira mais detalhes, eram cor-de-rosa - muitas vezes sonho colorido).

Fiquei então com esse problema na cabeça: como conceber um gradual estiramento de um intervalo, produzindo, assim, um efeito elástico? A solução encontrada, então, em caminhos, passagens e saídas (PENHA, 2008), foi fazer uma linha no clarinete que subisse gradualmente em microintervalos, em oitavos de tom, sobre um pedal do violino (Fig. 13), produzindo um efeito sonoro próximo ao de uma corda que se estica pouco a pouco antes de se estabilizar numa altura determinada, como quando se afina um violão. Ou seja, do problema de trabalhar elasticamente um intervalo, surgiu um outro problema referente a um fraseado microtonal, que passaria então a ser um elemento importante de minhas pesquisas composicionais.

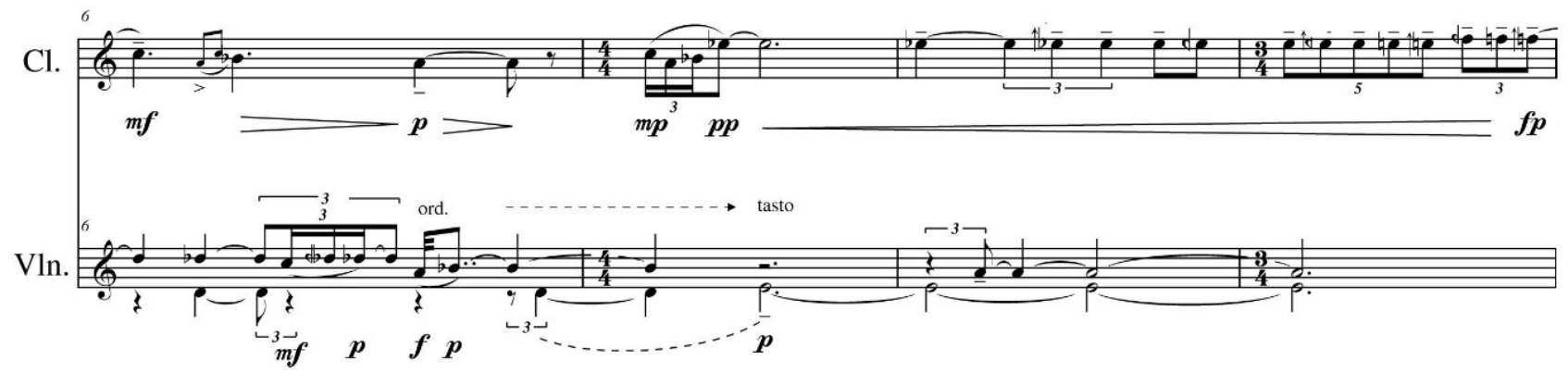

Fig. 13: Trecho de exploração da elasticidade de um intervalo harmônico em caminhos, passagens e saídas (PENHA, 2008)

O que me interessa no solfejo plástico é menos a forma adquirida em tal ou qual momento do processo de modulação formal do que a tensão entre a incidência de forças deformantes, a resistência dos materiais e as contínuas reconfigurações corporais resultantes. Assim, a plasticidade está diretamente ligada a processos de transformação 
que acontecem num escoamento temporal presente, a algo que, atual e virtualmente, faz um fluxo sonoro ser continuamente transformado em tempo real. Ao falar sobre algumas ideias que buscou elaborar em Volumina (1961), para órgão, peça do início do período de uma pesquisa composicional em busca de uma maior vitalidade rítmica e energética em sua escrita, Ligeti (2013 [1968], p.188) diz:

Eu imaginava uma música praticamente amorfa, em que os sons não tivessem mais função individualmente, mas onde as acumulações e as aglomerações de sons, assim como as relações de volume desses coletivos sonoros, fossem constitutivos da forma. Densificação, dissoluções, diversos momentos internos entre os aglomerados sonoros, acontecimentos tectônicos como avalanches, amontoamentos, sedimentações, mas também processos atmosféricos como evaporações, rarefações e outros fenômenos semelhantes articulam esta forma que, vista em sua globalidade, é de natureza contínua.

Nessa breve descrição sobre a elaboração e a percepção formal de Volumina, ${ }^{8}$ Ligeti evidencia, através da ampla exploração de substantivos abstratos derivados de verbos (densificação, dissolução, amontoamento etc.), um pensamento interessado em ações, em processos de transformação dos materiais que acontecem em tempo real, no próprio escoamento de um presente. Mas o que importa ao solfejo plástico não é a sucessão de presentes característica do escoamento temporal, em que um momento presente é substituído pela chegada do próximo. O caráter plástico de um procedimento composicional se apresenta, assim, no acontecimento que produz as contínuas transformações nos fluxos materiais. E o acontecimento, enquanto tal, não se restringe à sucessão de um passado, um presente e um futuro, seguindo a passagem dos presentes que se discerne, ${ }^{9}$ pois "há um presente do futuro, um presente do presente, um presente do passado, todos implicados no acontecimento, enrolados no acontecimento, logo simultâneos, inexplicáveis" (DELEUZE, 1985, p.132). São como pontos de vista, variados pontos de presente, tomados em simultaneidade. E não é o traçado que tais pontos formam o que mais interessa, embora o mapa de pontos singulares seja de extrema importância no acontecimento, mas, antes, a coexistência de tudo aquilo que se passou, se passa e se passará entre distintos pontos de presente tomados em simultaneidade. O solfejo plástico é um modo de conceber o próprio tempo musical, portanto, a partir de um presente puro, do acontecimento enquanto coexistência simultânea de diversos pontos de presente. É, portanto, um solfejo temporal voltado ao presente puro e se diferencia então por natureza de um solfejo arquitetural, voltado ao passado puro, e que, em música, se evidencia no pensamento da unidade e coerência formais, da distribuição mais ou menos hierárquica dos elementos individuais determinada por remissões, lembranças, voltas e retomadas como marcadores de uma macroforma mais ou menos predeterminada. ${ }^{10}$ Voltado ao acontecimento, à potência do verbo no infinitivo,

8 Sobre a plasticidade implicada na própria gestualidade físico-instrumental de Volumina, ver vídeo da interpretação do organista Lars Gjerde, acompanhado dos registrantes Scott Perkins e Aaron James: https://www.youtube.com/watch?v=vL2-fCXYTdw.

$9 \quad$ Deleuze (1985, p.132).

10 Sobre a diferença de natureza entre uma imagem-tempo plástica e uma imagem-tempo arquitetural, ver Deleuze (1985, p.137). 
o solfejo plástico atenta, portanto, às transformações incorporais naquilo que acontece num presente, não somente às misturas de corpos a que lhes correspondem; atenta aos processos de deformação que se atribui aos corpos, não somente a tal ou qual qualidade corporal atual resultante. ${ }^{11}$

A plasticidade em música por vezes tem a ver com o cruzamento entre diferentes sentidos, entre variados meios sensíveis e sensações, fazendo a escuta ser modulada pelo tato, pela gravidade, pela propriocepção, pela cinética etc. Aqui, penso novamente com Ligeti (1993, p.165), para quem

[...] a conversão involuntária de [sensações] óticas e táteis em sensações acústicas é habitual em mim. Eu quase sempre associo sons com cor, forma e textura; e forma, cor, e qualidade material como qualquer sensação acústica. Mesmo conceitos abstratos, como quantidades, relações, conexões e processos, parecem tangíveis para mim.

Em presque un murmure sans son (PENHA, 2014a), para quatro percussionistas, a plasticidade tátil foi um importante elemento na organização da peça, tendo sido explorada no nível concreto de tatilidade, implicado no encontro que faz um estimulador afetar uma superfície, pondo-a em vibração. Assim, atentando-se às qualidades e potências de diferentes regiões materiais de instrumentos de peles e metais, assim como a diversos modos e pontos de ataque com os dedos das mãos, que busquei nessa peça confrontar e dramatizar as deformações plásticas no aspecto tátil das texturas sonoras e de suas respectivas montagens.

Em presque un murmure sans son (PENHA, 2014a), a rugosidade é um elemento de extrema importância à caracterização das qualidades sonoras das diferentes partes da peça. São vários os elementos que se conjugam para a definição da rugosidade nas texturas que caracterizam cada parte. Com relação às qualidades sonoras de cada grão, as principais variáveis exploradas em suas diferenciações dizem respeito a seus modos de ataque e à qualidade dos materiais dos corpos envolvidos, que em suas combinações diversas possibilitam uma variedade tanto de perfis dinâmicos de ataques, por seus diferentes comportamentos de transientes, quanto de perfil dinâmico global, assim como dos coloridos tímbricos, mais ou menos harmônicos ou inarmônicos de acordo com a distribuição de energia em diferentes regiões formânticas. As propriedades implicadas na produção do som são exploradas e variam de acordo com a materialidade e as configurações do estimulador, da superfície vibratória e da caixa de ressonância, assim como com efeitos produzidos por seu funcionamento conjunto. Com relação às tramas, massas e texturas que tais grãos formam conjuntamente, suas qualidades são determinadas pelo modo de movimentação rítmica (regular em uníssono rítmico ou deslocamentos entre os instrumentos ou irregular), pela densidade horizontal variável, de acordo com a proximidade ou a distância entre os ataques dos grãos dispostos temporalmente, e ainda pela densidade vertical determinada pelas regiões espectrais que os aglomerados de 
grãos ocupam. Assim, a rugosidade é determinada pelas variações afetivas ${ }^{12}$ produzidas pela diversidade de ataques, com unhas, ponta dos dedos, polpa dos dedos, com dois ou três dedos, simultaneamente, ou de mão fechada; ou ainda por afetos ressonantes metálicos de gongos e tantãs, ou ressonantes de membranas e peles, como os tons, tímpano ou bombos; ou ainda, inversamente, por afetos abafados; ou ainda por afetos da vibração de uma superfície, que varia de acordo com o ponto de ataque se efetuar em seu centro ou em suas bordas, o que permite traçar linhas que passam por todo um contínuo de posições e produzem um correspondente efeito de filtro num determinado conteúdo espectral (Fig. 14); ou ainda por afetos mecânicos ligados à regularidade rítmica dos ataques, ou afetos mais orgânicos, por assim dizer, ligados a iterações irregulares, ou mais estocásticos, a sequências probabilísticas, portanto; ou ainda por afetos calmos, apressados, em aceleração ou desaceleração, implicados na vivacidade energética-rítmica da textura, assim como nas qualidades dos grãos, principalmente de seus ataques. Assim, a rugosidade é explorada a partir de toda uma variedade de afetos materiais sensíveis diferentemente elaborados e postos em interação, caracterizando e privilegiando, assim, tais ou quais qualidades e potências texturais dos sons.

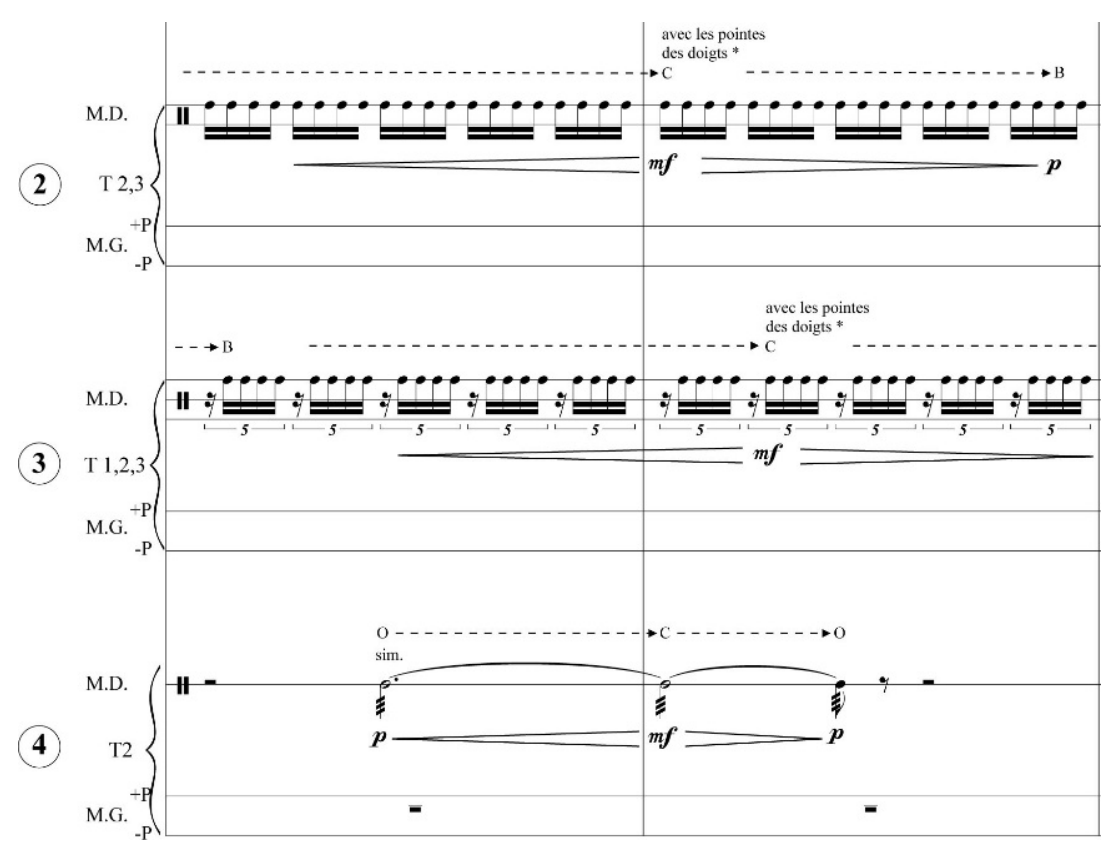

Fig. 14: Trecho da parte inicial de presque un murmure sans son (PENHA, 2014a)

Em Farfalhando (PENHA, 2015) para sax barítono e transformação eletrônica em tempo real, busquei trabalhar com a ideia de explorar um acontecimento numa paisagem, de micromovimentos de uma imagem. Nessa peça (que no momento não está ainda finalizada, mas em pleno processo de composição pelo trabalho colaborativo que se realiza junto ao saxofonista Pedro Bittencourt), toda a movimentação dos dedos, que pouco a pouco realizam a ação de fechar o tubo do instrumento, é pensada em relação com as variações de velocidade e movimento das folhas de árvores, arbustos, moitas, 
plantas, sob a ação de correntes de ar que também agem de acordo com variáveis de velocidade, densidade, direção, força. O que é trabalhado é uma dissociação entre as ações realizadas pelo aparelho fonador, de articulação dos sons e sustentação das colunas de ar, e as ações realizadas pelos dedos, que têm, por sua vez, sua potencialidade percussiva autonomizada e também explorada composicionalmente. A peça de alguma maneira segue uma pesquisa iniciada em Vento sob os dedos (PENHA, 2014b), para flauta solo, que em sua primeira parte faz com que um movimento mecânico dos dedos, que gradualmente varrem toda a extensão dos furos e chaves presentes no tubo da flauta, atue em contraponto com correntes de ar que dão mais ou menos foco ao som ordinário da flauta, por um jogo que inclui a exploração de modos de sopro que produzem ruídos brancos e sons mistos entre nota e ruído. $O$ que interessa nessa concepção é o desenvolvimento de uma escrita que busca autonomizar determinados comportamentos sensório-motores implicados nas diferentes práticas musicais instrumentais para organizá-los composicionalmente, a partir de lógicas operacionais que tornam a escrita na partitura indissociável das singularidades do instrumento para o qual ela é pensada.

É também mais recentemente que tenho valorizado e trabalhado composicionalmente as potencialidades singulares do silêncio e dos sons que se the avizinham. Tenho particular interesse em certos efeitos produzidos pela escuta de um material em pianíssimo, quase silencioso. Assim, tenho trabalhado algumas paisagens em que é necessário que o máximo possível de silêncio do público e do ambiente se estabeleça como condição de possibilidade da escuta dos sons produzidos pelos músicos. Tenho, desse modo, me interessado em levar a escuta a graus extremamente baixos de amplitude sonora, ao propor que toda a dramaticidade das gestualidades, das articulações, dos movimentos dinâmicos e rítmicos, que determina que o desenrolar de um trecho silencioso só se concretize se os presentes no espaço de performance assumirem efetivamente um estado de silêncio. $O$ desafio é atrair e instigar os ouvintes a se atentarem e se envolverem com essa quietude necessária que a peça propõe. Trata-se, portanto, de convidar os ouvintes a participarem ativamente na produção de um ambiente silencioso que atuará como condição de aparecimento de paisagens sonoras. É um modo de tentar desfazer a rigidez caricatural do silêncio de submissão ${ }^{13}$ típico do bom comportamento social em salas de concerto, propondo um silêncio criativo que envolva ativamente os ouvintes na construção de um ambiente em que o mínimo de som produzido (seja na plateia, no palco, na coxia, dos sons exteriores que vazam) participa diretamente do acontecimento musical. Entretanto, não se trata de maneira alguma de um silêncio completamente cômodo e confortável, mas, antes, vivo, instável e constantemente variável. Assim, me interesso pelo incômodo do estado de imobilidade corporal em que ficam alguns ouvintes, pois evitam se mexer nas suas cadeiras para não produzir ruído na sala; ou também pela dificuldade em se fazer ouvir que um som em pianíssimo cria, obrigando o ouvinte a buscar, a ir atrás de um som para criá-lo, visto que o que lhe chega não é um som pronto e garantido por um alto nível de decibéis, mas algo que necessita de uma maior atenção e focalização do ouvido para se definir; ou ainda a tensão que surge quando 
um extremo silêncio se instaura numa sala contendo um tanto de ouvintes, que faz por vezes com que a escuta e a participação dos presentes adquiram um caráter quase ritual. É portanto um certo gosto pelas instabilidades o que me aproxima do silêncio, um gosto pelo risco de a realização sonora de uma composição não funcionar, ou seja, pela sensação de dúvida que surge pelo perigo de uma composição que escrevi não parar em pé, de se romper o fio que a conduz e, com isso, ela perder toda sua consistência.

Por que haveria de ser diferente em música, se já o "viver é muito perigoso"? ${ }^{14}$

\section{Considerações finais}

No presente artigo foram abordados: o problema da diferenciação de modos de escuta que são trabalhados e pensados no próprio processo composicional; o problema do povoamento por motivos gestuais como personagens rítmicos que estão constantemente em relação dinâmica com outros personagens e consequentemente com a textura global; o problema do cruzamento contínuo das vozes e das linhas, que obscurece a escuta da individualidade das linhas em favor de uma escuta dos movimentos e repousos, das velocidades e lentidões; o problema da abertura e ocupação gradual do espaço, que aponta para a multiplicidade dos planos potencialmente ocupáveis; o problema da busca por fraseados não convencionais; a relação do plano sonoro com imagens sensoriais de naturezas não auditivas; a potência do caráter plástico implicado nas transformações de objetos e texturas musicais.

Os problemas composicionais abordados, se pensados temporalmente, podem talvez ser observados sob duas perspectivas: do ponto de vista do escoamento temporal, em que funcionam como operadores que produzem e controlam, mais ou menos, a dinamicidade dos elementos postos em jogo em uma certa paisagem sonora, com seus subsequentes efeitos perceptivos na escuta; e do ponto de vista da produção de um corte ${ }^{15}$ em que o tempo é tido como um acontecimento que, mais ou menos bruscamente, em micro ou macroescala, irrompe o fluxo sonoro de uma paisagem, como se nela abrisse uma fenda, por meio da participação ativa de novos elementos, que têm a potência de produzir uma deformação plástica e de desencadear a abertura e o caminhar a outras paisagens sonoras. Trata-se, portanto, de problemas composicionais que contribuem para se pensar modos de inserir o tempo, seja em escoamento ou acontecimental, tanto na composição musical quanto na própria prática de análise musical.

\section{Referências bibliográficas}

ANÔNIMO. [1396-1399] O Virgo Splendens. In: VIRET, Jaques (org.). Le Llibre Vermell de Montserrat (XIVe siècle), édition pour voix à cappella, fac-símile. Lyon: Éditions à Cœur Joie, 2004. 128 p. 
DELEUZE, Gilles. Cinéma 2: l'image-temps. Paris: Minuit, 1985.

DELEUZE, Gilles. Espinosa e o problema da expressão. Trad. Luiz B. L. Orlandi. São Paulo: Ed. 34, 2017 [1968].

DELEUZE, Gilles; GUATTARI, Félix. O que é a filosofia? Trad. Bento Prado Jr. e Alberto Alonso Muñoz. São Paulo: Ed. 34, 1992 [1991].

DELEUZE, Gilles; GUATTARI, Félix. Mil Platôs: capitalismo e esquizofrenia 2. Trad. Ana Lúcia de Oliveira e Lúcia Cláudia Leão. São Paulo: Ed. 34, 1995. V. 2. [Mille Plateaux capitalisme et squizophrénie 2. Paris: Minuit, 1980]

FERRAZ, Silvio. Notas do caderno amarelo: a paixão do rascunho. Tese (Livre Docência em Criação Musical) - Instituto de Artes, Universidade Estadual de Campinas, Campinas, 2007. Disponível em: http://sferraz.mus.br/principal_ing.htm.

FERRAZ, Silvio. Músicas e Territórios. Polêm!ca, v. 9, p. 62-130, 2010. Disponível em: http://www.e-publicacoes.uerj.br/index.php/polemica/article/viewFile/2815/1942.

GUATTARI, Félix. Caosmose: um novo paradigma estético. São Paulo: Ed. 34, 1992.

LIGETI, G. States, events and transformations. Perspectives of new music, Seattle, Washington University Press, v. 31, n. 1. 1993 [1960]. p. 164-171.

LIGETI, G. Sur Volumina. In: LIGETI, G. L'atelier du compositeur. Trad. francês Catherine Fourcassié, Pierre Michel et al. Genebra: Contrechamps, 2013 [1968]. p. 187-188.

MESSIAEN, Olivier. Techniques de mon langage musical. Paris: Leduc, 1940.

OLIVEIRA, Franscisco Zmekhol Nascimento de. A escrita rítmica de Olivier Messiaen e seus desdobramentos em outros aspectos de sua prática composicional. $195 \mathrm{f}$. Dissertação (Mestrado em Música) - Instituto de Artes, Universidade Estadual de Campinas, Campinas, 2003.

ORLANDI, Luiz B. L. Um gosto pelos encontros. In: ORLANDI, Luiz B. L. Arrastões na imanência. Campinas: Phi, 2018. p. 395-417.

PACE, Ian. Composição e performance podem ser, e frequentemente tem sido performance. Vórtex, Curitiba, v. 8, n. 1, p. 1-23, 2020 [2015]. Trad. Vitória Liz P. Louveira e William Teixeira. Disponível em: http://vortex.unespar.edu.br/pace_v8_ n1.pdf. 
PAQUIN, Louis-Claude. La Méthodologie. In: PAQUIN, Louis-Claude. Méthodologie de la recherche création. Montréal: Université du Québec à Montréal, 2014. Disponível em: http://lcpaquin.com/methoRC/MethoRC_methodologie.pdf/.

PENHA, Gustavo. caminhos, passagens e saídas. Clarinete, violino, violoncelo e piano. 2008. 1 partitura.

PENHA, Gustavo. Reescrituras na música dos séculos XX e XXI. Dissertação (Mestrado em Música) - Instituto de Artes, Universidade Estadual de Campinas, Campinas, 2010a.

PENHA, Gustavo. Nenhum, nenhuma. Piano solo. 2010b. 1 partitura.

PENHA, Gustavo. per suoanre in um teatro vuoto. Quarteto de cordas. 2012. 1 partitura.

PENHA, Gustavo. estudo sobre gravitação. para quarteto de cordas. 2013 [2011-2013]. 1 partitura.

PENHA, Gustavo. presque um murmure sans son. Quatro percussionistas. 2014a. 1 partitura.

PENHA, Gustavo. Vento sob os dedos. Flauta solo. 2014b. 1 partitura.

PENHA, Gustavo. Zanzando em zigue-zague. Flauta traverso, teorba e violoncelo. 2014c. 1 partitura.

PENHA, Gustavo. Farfalhando. Sax barítono e eletrônica em tempo real. 2015. 1 partitura.

PENHA, Gustavo. Entre escutas e solfejos: afetos e reescrita crítica na composição musical. Tese (Doutorado em Música) - Instituto de Artes, Unicamp, Campinas, 2016.

PENHA, Gustavo. Música e a produção de afetos. Vortéx, Curitiba, v. 7, n. 1, p. 1-29, 2019.

ROSA, João Guimarães. Grande Sertão: Veredas. Rio de Janeiro: Nova Fronteira, 2001 [1956].

SIMONDON, Gilbert. L'amplification dans les processus d'information. In: SIMONDON, Gilbert. Communication et information: cours et conférences. Chatou: Éd. de la Transparence, 2010 [1962]. 
STRAVINSKY, Igor; CRAFT. Robert. Conversas com Igor Stravinsky. Trad. Stella Rodrigo Octavio Moutinho. São Paulo: Perspectiva, 2004 [Conversations with Igor Stravinsky. New York: Doubleday \& Company, 1959].

VIRET, Jacques. Commentaires des chants. In: VIRET, Jacques. Le Llibre Vermell de Montserrat (XIVe siècle): édition pour voix a cappella, fac-símile. Lyon: Éditions à Cœur Joie, 2004. 1 partitura. 44 p.

ZOURABICHVILI, François. Deleuze: uma filosofia do acontecimento. São Paulo: Ed. 34, 2016 [2004]. 